Check for updates

Cite this: RSC Adv., 2018, 8, 42200

\title{
Synthesis and characterization of a single phase zeolite A using coal fly ash
}

\author{
Xiaoyu Ren, Lifeng Xiao, Ruiyang Qu, Shaojun Liu, ${ }^{\star}$ Dong Ye, Hao Song, Weihong Wu, \\ Chenghang Zheng, Xuecheng Wu and Xiang Gao (DD*
}

Zeolitization of coal fly ash (CFA) provides a potential alternative for creating high-added-value products from this hazardous solid waste. In this work, a single phase zeolite A with high crystallinity was successfully synthesized from CFA via the alkali fusion hydrothermal method. X-ray diffraction (XRD), scanning electron microscopy (SEM), X-ray fluorescence (XRF), Fourier transform infrared (FT-IR) spectroscopy, $\mathrm{N}_{2}$ physisorption, and solid-state MAS NMR spectra were applied to characterize assynthesized zeolites. Results indicated that the type and purity of zeolite were closely related to the synthesis conditions and parameters. A well-defined cubic shape of zeolite A with a specific surface area of $43.7 \mathrm{~m}^{2} \mathrm{~g}^{-1}$ was obtained at a low temperature of $75^{\circ} \mathrm{C}$ during hydrothermal treatment for $18 \mathrm{~h}$. The ammonium cation exchange capacity (CEC) test showed an impressive value of $232.2 \mathrm{mmol} 100 \mathrm{~g}^{-1}$ over prepared zeolite A, which was about 22 times that of the original CFA and close to commercial zeolite A. These results pave the way for the exploitation and utilization of the CFA.

Received 7th November 2018

Accepted 12th December 2018

DOI: $10.1039 / c 8 r a 09215 j$

rsc.li/rsc-advances
MFI exhibits an excellent catalytic epoxidation performance of styrene and high separation capacity of $\mathrm{CO}_{2}$ and $\mathrm{NO}_{2} \cdot{ }^{13}$

Among hundreds of different types of zeolites, zeolite $\mathrm{A}$ is one of great importance because of the small aperture of about $4 \AA$, and high molar ratio of aluminum to silicon $(\sim 1)$, which can provide a large number of sites for cation exchange. ${ }^{\mathbf{1 4 , 1 5}}$ Thanks to the outstanding characteristics such as non-toxicity and high thermal stability, ${ }^{\mathbf{1 6}}$ zeolite $\mathrm{A}$ has been extensively used for waste treatment, ${ }^{17-19}$ and product separation. ${ }^{20}$ However, the high cost resulting from the expensive precursors used mainly limits the wide applications of zeolite A. Recently, great efforts have been made to solve this problem. ${ }^{21-24}$

Considering that silicon and aluminum are the main components of CFA, it is reasonable to conceive the idea of prepare zeolite A from CFA. ${ }^{25}$ However, insoluble crystalline phases such as quartz and mullite introduced from CFA may reduce the cation exchange capacity (CEC) and limit the application of zeolites. ${ }^{26}$ To address this problem, the addition of alkali to fly ash during calcination could get rid of these crystalline phases, which would be beneficial for the formation of pure phase in zeolite products. ${ }^{27,28}$ Besides, impurities such as iron were also reported to negatively affect the synthesis of zeolites. ${ }^{29}$ As a result, acid treatment is favorable to remove iron and other heavy metals and further improve the CEC and crystallinity of zeolites. ${ }^{30}$

In this work, a single phase zeolite A was successfully synthesized based on CFA by the alkali fusion hydrothermal method. Key parameters such as the mass ratios $\mathrm{NaOH}$ to fly ash, $\mathrm{NaOH}$ melt temperatures, liquid-solid ratios, hydrothermal temperatures and time have been systematically 
investigated. In addition, the effect of acid treatment on iron removal were carefully discussed in this paper.

\section{Experimental}

\subsection{Materials and reagents}

The CFA was provided from Datang International Power Generation Co. Ltd. (Zhejiang Province, China). $\mathrm{NaAlO}_{2}, \mathrm{NaOH}, \mathrm{HCl}$ and $\mathrm{NH}_{4} \mathrm{Cl}$ were purchased from Sinopharm Chemical Reagent Co. Ltd. Deionized water was used in all solution preparations.

\subsection{Preparation of zeolite A}

2.2.1 Acid pretreatment. $10 \mathrm{~g}$ of dried CFA was separately refluxed in 50-300 $\mathrm{mL} \mathrm{HCl}$ solution (1.5-25\%) at $45-95{ }^{\circ} \mathrm{C}$ for 0.5-4 $\mathrm{h}(500 \mathrm{rpm})$ to remove $\mathrm{Fe}_{2} \mathrm{O}_{3}$. At the end of the reaction, the obtained powder was centrifuged and washed until the $\mathrm{pH}$ value of rinsing solution reached $c a$. 7. Finally, the obtained powder was dried overnight.

2.2.2 Preparation of zeolite A. $5.0 \mathrm{~g}$ acid-treated CFA, $2.05 \mathrm{~g}$ $\mathrm{NaAlO}_{2}($ molar ratio of $\mathrm{Si} / \mathrm{Al}=1)$ and a desired amount of $\mathrm{NaOH}$ (to adjust the mass ratio of $\mathrm{NaOH}$ to fly-ash between 0.5 and 2.0) were grounded and mixed well in a mortar. The mixed sample was separately calcined at high temperatures $\left(550-850^{\circ} \mathrm{C}\right)$ in air for $2 \mathrm{~h}$. After cooling to room temperature, the acquired solid product was grounded, separately mixed with $5-45 \mathrm{~mL}$ of $\mathrm{H}_{2} \mathrm{O}$ and then aged for $12 \mathrm{~h}$ under stirring. The solid-liquid mixture was then sealed in a autoclave and separately kept at $60-95^{\circ} \mathrm{C}$ for $6-24 \mathrm{~h}$. The resulting solid was cooled to room temperature, collected and washed until the $\mathrm{pH}$ value reached 7-8. Finally, the obtained solid was dried overnight at $100{ }^{\circ} \mathrm{C}$. The resulting product was named as ZFA.

\subsection{Cation exchange capacity (CEC) test}

CEC was evaluated by a straightforward principle of ion exchange, in which $\mathrm{Na}^{+}$ions in the three-dimensional structure of zeolite are replaced by $\mathrm{NH}_{4}{ }^{+}$ions of an ammonium-containing solution. ${ }^{31}$ The suspension, which was vibrated at $25^{\circ} \mathrm{C}$ for $24 \mathrm{~h}$, consisted of $0.5 \mathrm{~g}$ ZFA and $50 \mathrm{~mL}$ of $1000 \mathrm{mg} \mathrm{L^{-1 }} \mathrm{NH}_{4}^{+}$solution. The $\mathrm{NH}_{4}^{+}$ concentration was measured with a UV spectrophotometry $(\mathrm{HACH}$, DR 5000, America) at $395 \mathrm{~nm}$ by Nessler's reagent spectrophotometry. ${ }^{32}$ The functional relationship between absorbance and $\mathrm{NH}_{4}{ }^{+}$content in solution was obtained according to Chinese standard HJ 535-2009. Then the value of CEC was calculated by the difference between the original reactive concentration and the equilibrium one. The experiments were repeated three times and the mean value was taken to reduce uncertainty.

\subsection{Characterizations}

Crystal phase analysis of all substances were determined using X-ray diffraction spectroscopy (Rigaku, D/max-2200, Japan) with $2 \theta$ between $5^{\circ}$ and $60^{\circ}$ using $\mathrm{Cu} \mathrm{K} \alpha$ radiation. The relative “\% crystallinity" of product was counted based on eqn (1). ${ }^{33}$

$\%$ crystallinity $=\left(\frac{\sum \text { integrated peak areas of sample }}{\sum \text { integrated peak areas of commercial zeolite }}\right)$ $\times 100$
Table 1 Chemical ingredients of CFA, CFA with acid leaching to remove iron oxides (acid-CFA) and ZFA (wt\%)

\begin{tabular}{lccc}
\hline Ingredients & CFA & Acid-CFA & ZFA \\
\hline $\mathrm{SiO}_{2}$ & 44.7 & 60.1 & 40.6 \\
$\mathrm{Al}_{2} \mathrm{O}_{3}$ & 26.2 & 24.8 & 33.2 \\
$\mathrm{CaO}$ & 10.4 & 2.41 & 0.88 \\
$\mathrm{Fe}_{2} \mathrm{O}_{3}$ & 8.97 & 5.11 & 1.62 \\
$\mathrm{TiO}_{2}$ & 2.41 & 2.35 & 0.82 \\
$\mathrm{Na}_{2} \mathrm{O}$ & 0.76 & 0.91 & 21.9 \\
Others & 6.56 & 4.32 & 0.88 \\
$\mathrm{Si} / \mathrm{Al}$ & 1.44 & 2.06 & 1.04
\end{tabular}

The surface morphology of all substances were identified by scanning electron microscope (SEM, FEI Quanta 400 FEG). The surface nature of the prepared samples were investigated using Fourier transform infrared spectroscopy (FTIR) in the range of $400-4000 \mathrm{~cm}^{-1}$ (Nicolet NEXUS 6700). The specific surface area, total pore volume and pore size distribution were measured by the way of BET technique (Quantachrome Autosorb-1 instrument). Before adsorption, the samples were degassed at $350{ }^{\circ} \mathrm{C}$ for $8 \mathrm{~h}$. Solid-state NMR experiments were performed on a Bruker AVANCE III 400 WB spectrometer with the X channel of
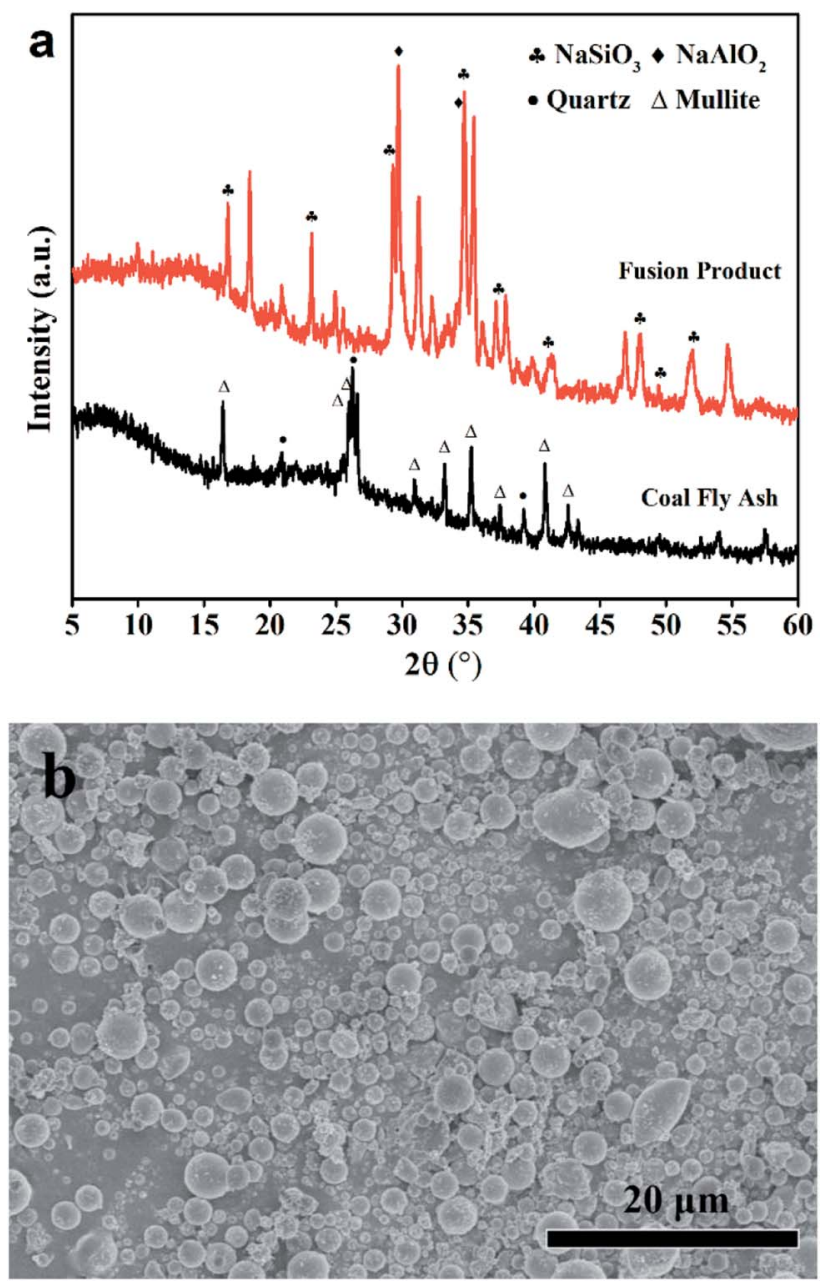

Fig. 1 (a) XRD patterns of the CFA and the fusion product; (b) SEM image of the CFA. 

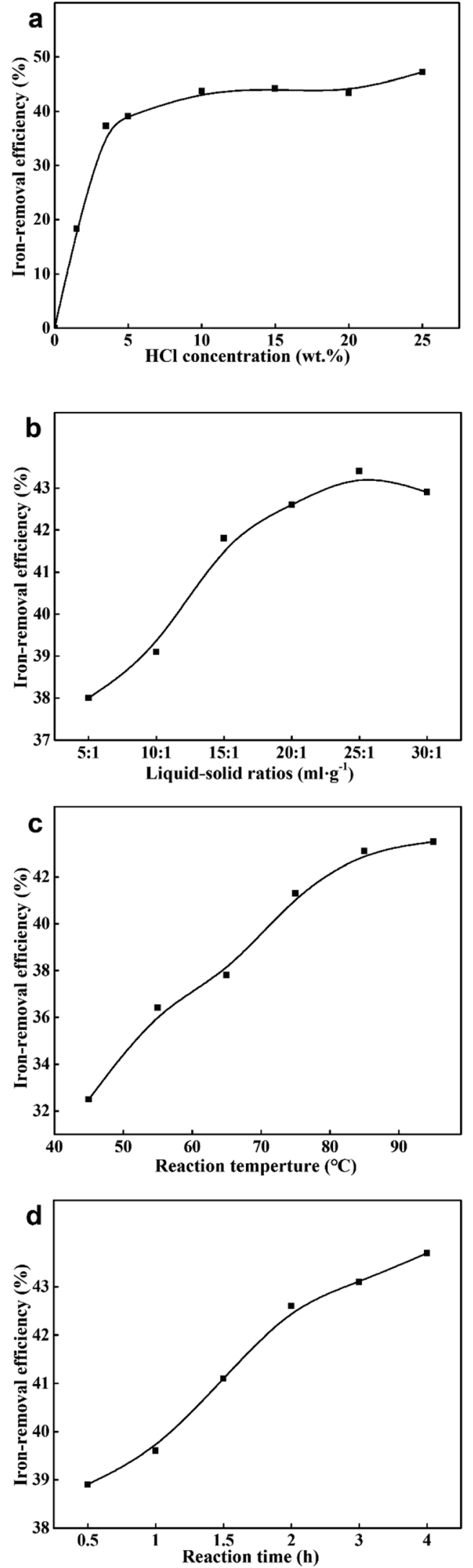

Fig. 2 Iron-removal efficiency at different (a) $\mathrm{HCl}$ concentration; (b) liquid-solid ratios; (c) reaction temperature; (d) reaction time.

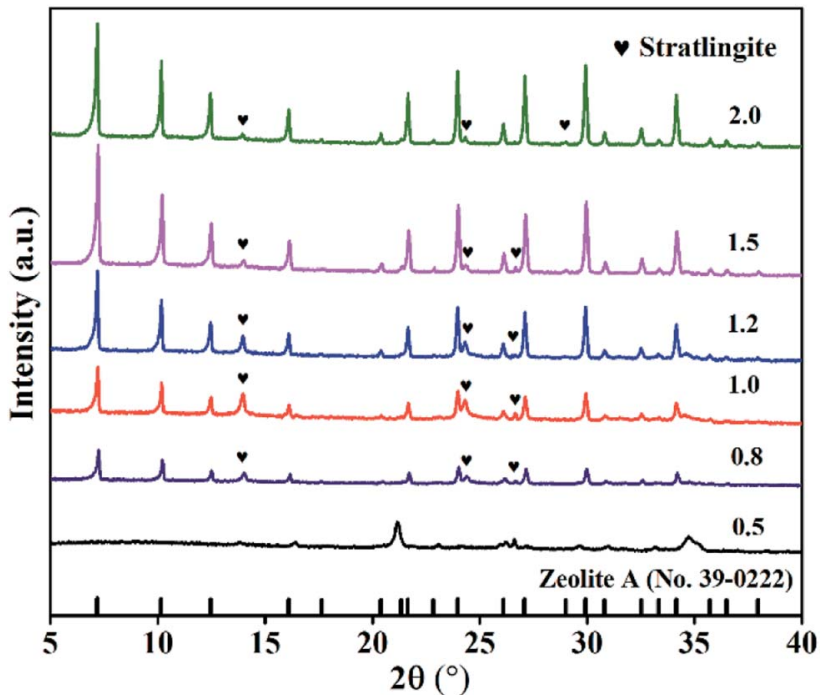

Fig. 3 XRD spectra of products with different mass ratios of $\mathrm{NaOH}$ to fly ash ( $\mathrm{NaOH}$ melt treatment: $650{ }^{\circ} \mathrm{C}, 2 \mathrm{~h}$; hydrothermal treatment: $85^{\circ} \mathrm{C}, 6 \mathrm{~h}$, liquid/solid $\left.=5, \mathrm{Si} / \mathrm{Al}=1\right)$.

104.27 $\mathrm{MHz}$ for ${ }^{27} \mathrm{Al}$ and $79.50 \mathrm{MHz}$ for ${ }^{29} \mathrm{Si}$. The standard of chemical shifts were referenced to the resonances of $\left[\mathrm{Al}\left(\mathrm{H}_{2} \mathrm{O}\right)_{6}\right]^{3+}\left({ }^{27} \mathrm{Al}\right)$ and 3-(trimethylsilyl)-1-propanesulfonic acid sodium salt $\left({ }^{29} \mathrm{Si}\right)$, respectively.

\section{Results and discussion}

\subsection{Coal fly ash characterization and iron removal}

The chemical ingredients of CFA are shown in Table 1 . The total content of $\mathrm{SiO}_{2}$ and $\mathrm{Al}_{2} \mathrm{O}_{3}$ was found to be high than $70 \%$. The XRD pattern in Fig. 1(a) suggested that the CFA sample contained large amounts of quartz and mullite. The broad peak at

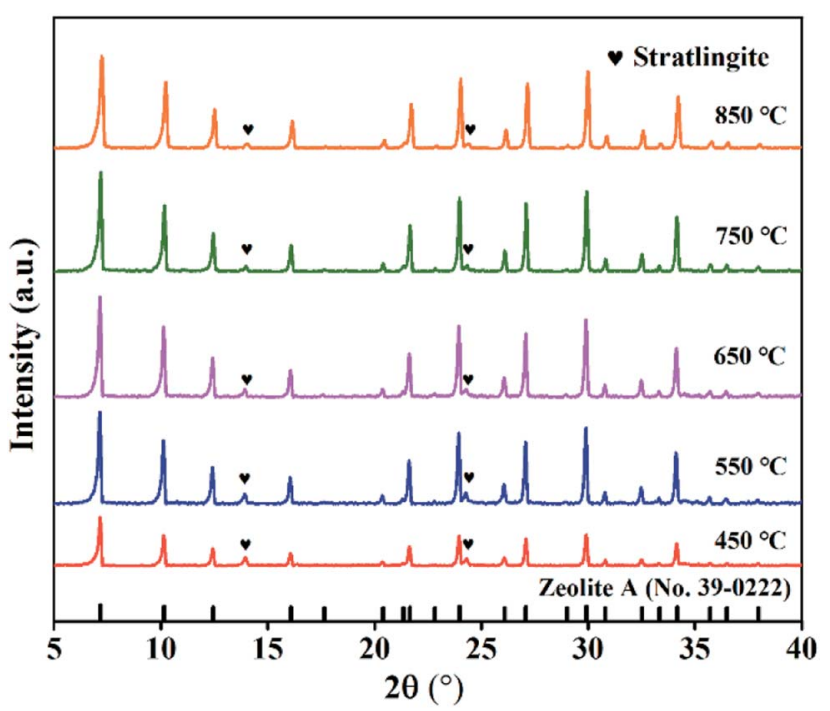

Fig. 4 XRD patterns of products at different $\mathrm{NaOH}$ melt temperatures ( $\mathrm{NaOH}$ melt treatment: $\mathrm{NaOH} / \mathrm{CFA}=1.5,2 \mathrm{~h}$; hydrothermal treatment: $85^{\circ} \mathrm{C}, 6 \mathrm{~h}$, liquid/solid $=5, \mathrm{Si} / \mathrm{Al}=1$ ). 

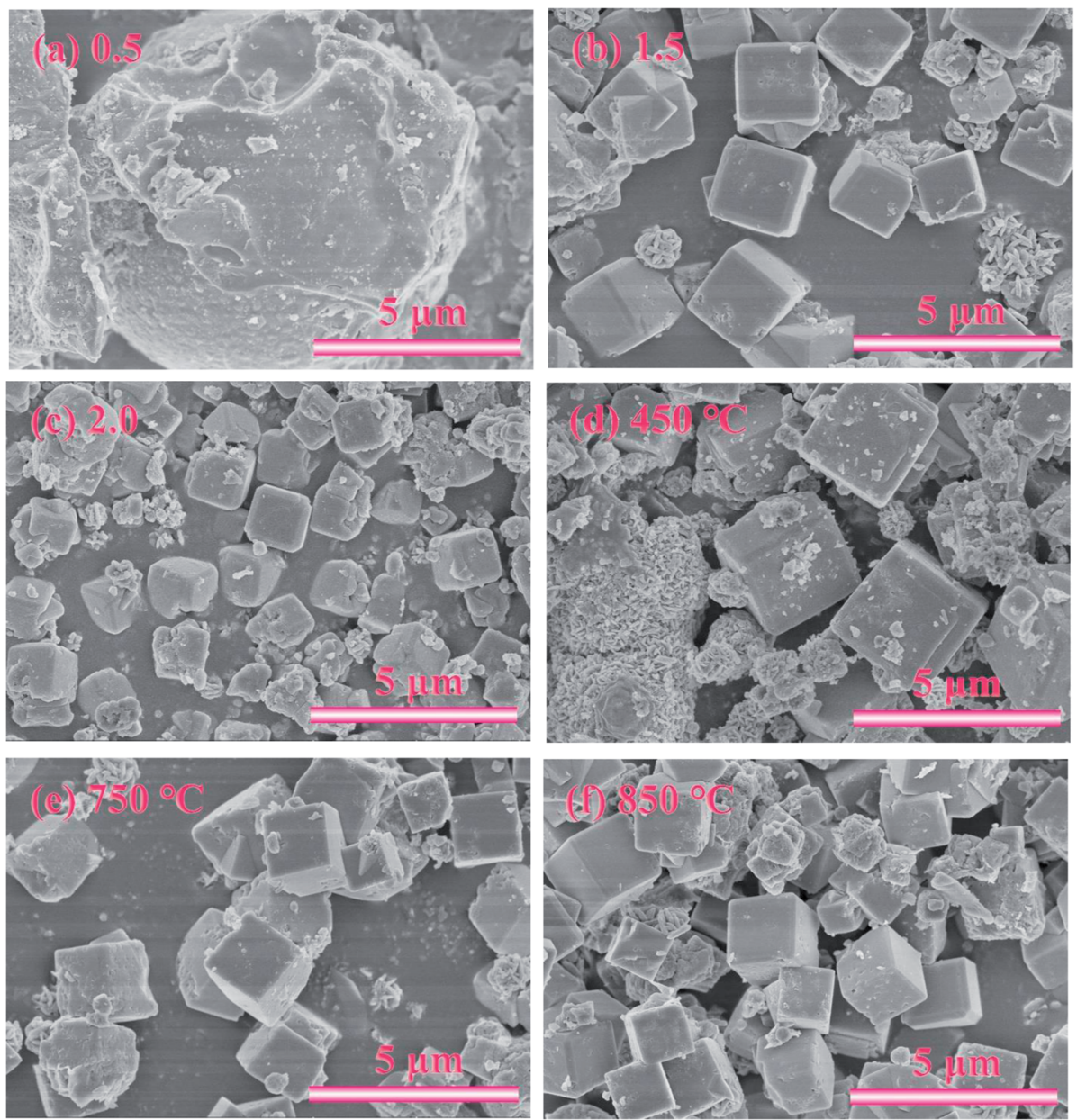

Fig. 5 SEM images of samples prepared with different mass ratios of $\mathrm{NaOH}$ to fly ash (a) 0.5 , (b) 1.5, (c) $2.0\left(\mathrm{NaOH}\right.$ melt treatment: $650{ }^{\circ} \mathrm{C}, 2 \mathrm{~h}$; hydrothermal treatment: $85^{\circ} \mathrm{C}, 6 \mathrm{~h}$, liquid/solid $=5, \mathrm{Si} / \mathrm{Al}=1$ ) and different $\mathrm{NaOH}$ melt treatment temperatures (d) $450{ }^{\circ} \mathrm{C}$, (e) $750{ }^{\circ} \mathrm{C}$, (f) $850{ }^{\circ} \mathrm{C}$ $\left(\mathrm{NaOH}\right.$ melt treatment: $\mathrm{NaOH} / \mathrm{CFA}=1.5,2 \mathrm{~h}$; hydrothermal treatment: $85^{\circ} \mathrm{C}, 6 \mathrm{~h}$, liquid/solid $\left.=5, \mathrm{Si} / \mathrm{Al}=1\right)$.

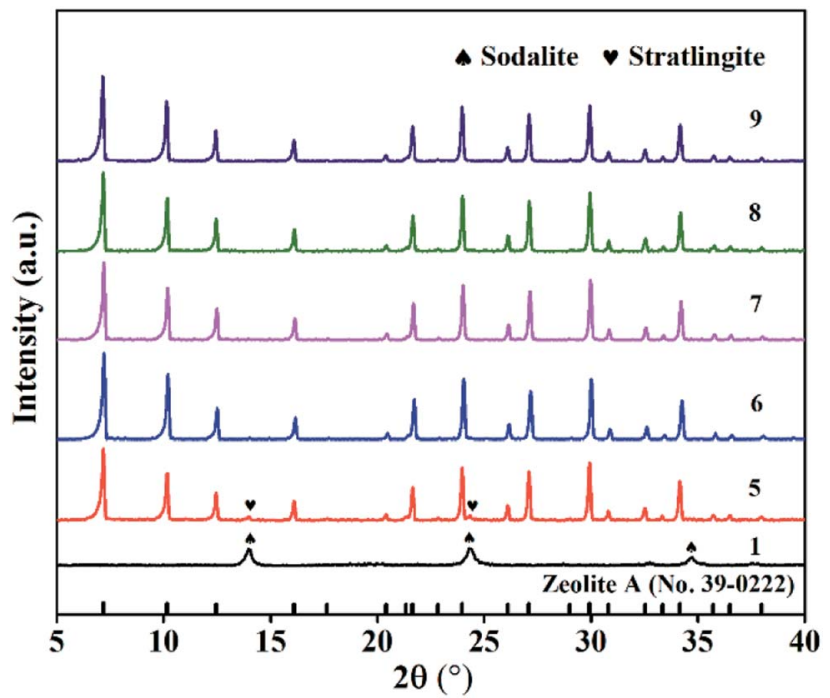

Fig. 6 XRD spectra of samples at different ratios of liquid to solid $\left(\mathrm{NaOH}\right.$ melt treatment: $\mathrm{NaOH} / \mathrm{CFA}=1.5,750^{\circ} \mathrm{C}, 2 \mathrm{~h}$; hydrothermal treatment: $85^{\circ} \mathrm{C}, 6 \mathrm{~h}, \mathrm{Si} / \mathrm{Al}=1$ ).

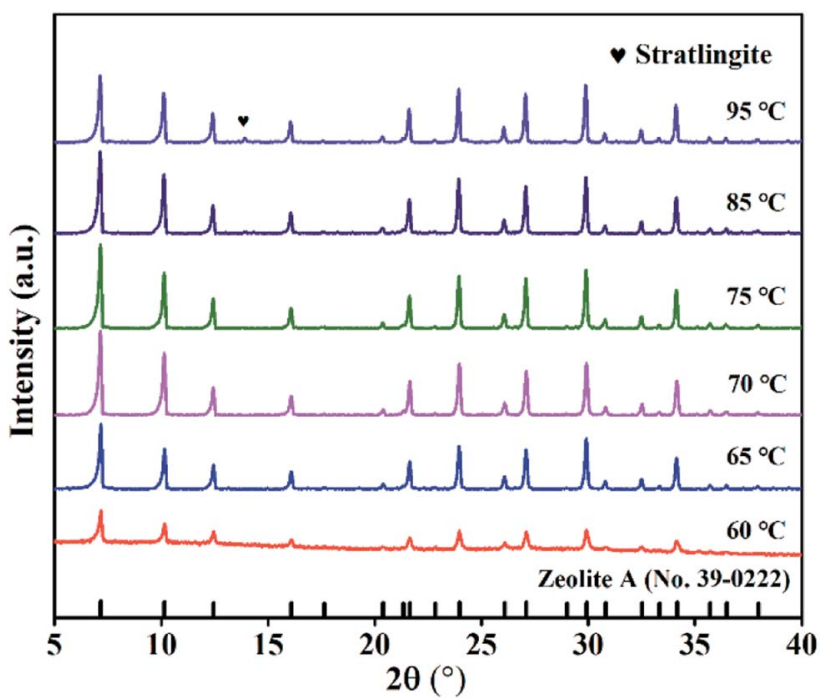

Fig. 7 XRD spectra of samples at various hydrothermal temperatures $\left(\mathrm{NaOH}\right.$ melt treatment: $\mathrm{NaOH} / \mathrm{CFA}=1.5,750{ }^{\circ} \mathrm{C}, 2 \mathrm{~h}$; hydrothermal treatment: $6 \mathrm{~h}$, liquid/solid $=8, \mathrm{Si} / \mathrm{Al}=1$ ). 


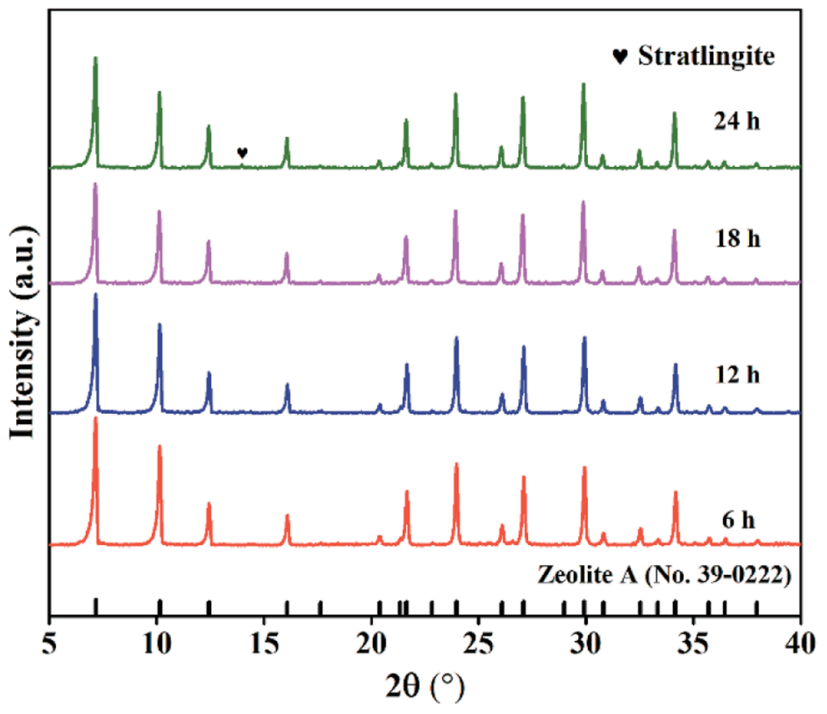

Fig. 8 XRD spectra of samples after different hydrothermal time $\left(\mathrm{NaOH}\right.$ melt treatment: $\mathrm{NaOH} / \mathrm{CFA}=1.5,750{ }^{\circ} \mathrm{C}, 2 \mathrm{~h}$; hydrothermal treatment: $75^{\circ} \mathrm{C}$, liquid/solid $=8, \mathrm{Si} / \mathrm{Al}=1$ ).

$26^{\circ}$ was classified as amorphous silicon-aluminum materials. SEM image in Fig. 1(b) shows that the CFA particles are spherical with the size smaller than $6 \mu \mathrm{m}$.
A series of parameters were adjusted to seek the optimum method for iron removal, such as $\mathrm{HCl}$ concentration, liquidsolid ratios, reaction temperature and reaction time. As is given in Fig. 2, a maximum removal efficiency (43.1\%) was obtained under the condition of $5 \mathrm{wt} \%$ of $\mathrm{HCl}$ and a liquid-solid ratio of 20 at $85{ }^{\circ} \mathrm{C}$ for $3 \mathrm{~h}$.

\subsection{Effect of mass ratios $\mathrm{NaOH}$ to fly-ash}

The XRD patterns in Fig. 1(a) illustrate the transformation process of fly ash components during $\mathrm{NaOH}$ etching. Compared with the original CFA, a noticeable change has taken place. $\mathrm{NaAlO}_{2}$ and $\mathrm{Na}_{2} \mathrm{SiO}_{3}$ phases appeared at the cost of the diminishment of quartz and mullite phases, as explained in eqn (2):

$$
\mathrm{NaOH}+x \mathrm{Al}_{2} \mathrm{O}_{3} \cdot y \mathrm{SiO}_{2} \rightarrow \mathrm{Na}_{2} \mathrm{SiO}_{3}+\mathrm{NaAlO}_{2}
$$

$\mathrm{NaAlO}_{2}$ and $\mathrm{Na}_{2} \mathrm{SiO}_{3}$ could dissolve easily in water and eventually make up the zeolite framework. ZFA zeolites in Fig. 3 were acquired with different mass ratios of $\mathrm{NaOH}$ to fly ash from 0.5 to 2.0. No peaks for zeolite A was found at the mass ratio of 0.5. When increasing the ratios, zeolite A (JCPDS card no. 39-0222) became the main crystalline phase and the intensity of diffraction peaks also increased. It was also observed that the peak intensity was the highest when the ratio reached 1.5. In
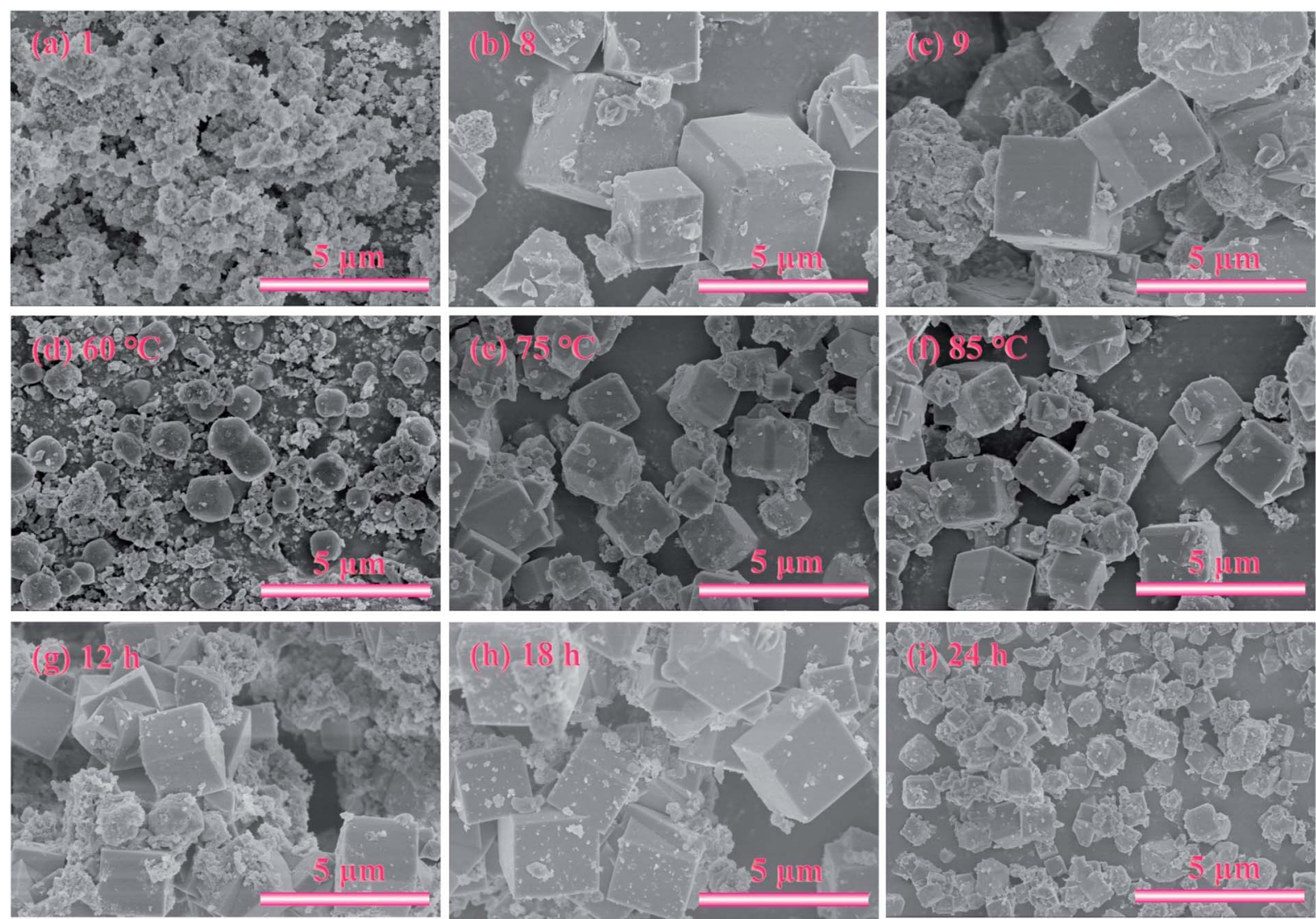

Fig. 9 SEM images of samples prepared with different liquid-solid ratios (a) 1, (b) 8, (c) 9 ( $\mathrm{NaOH}$ melt treatment: $\mathrm{NaOH} / \mathrm{CFA}=1.5,750{ }^{\circ} \mathrm{C}, 2 \mathrm{~h}$; hydrothermal treatment: $\left.85^{\circ} \mathrm{C}, 6 \mathrm{~h}, \mathrm{Si} / \mathrm{Al}=1\right)$; different hydrothermal temperatures (d) $60{ }^{\circ} \mathrm{C},(\mathrm{e}) 75^{\circ} \mathrm{C},(\mathrm{f}) 85^{\circ} \mathrm{C}(\mathrm{NaOH}$ melt treatment: $\mathrm{NaOH} /$ $\mathrm{CFA}=1.5,750^{\circ} \mathrm{C}, 2 \mathrm{~h}$; hydrothermal treatment: $6 \mathrm{~h}$, liquid/solid = 8, Si/Al = 1) and different hydrothermal time (g) $12 \mathrm{~h}$, (h) $18 \mathrm{~h}$, (i) $24 \mathrm{~h}(\mathrm{NaOH}$ melt treatment: $\mathrm{NaOH} / \mathrm{CFA}=1.5,750{ }^{\circ} \mathrm{C}, 2 \mathrm{~h}$; hydrothermal treatment: $75^{\circ} \mathrm{C}$; liquid/solid $=8$, Si/Al $=1$ ). 
contrast, the peaks of zeolite A decreased slightly at the ratio of 2.0. Fig. 10(a) shows that the variation of CEC values of ZFA is consistent with the XRD results. With low $\mathrm{NaOH}$, the inert crystals were not completely transformed into soluble silicoaluminate, resulting in a low yield of zeolite A and low CEC value. However, with an excessively high amount of $\mathrm{NaOH}$, parts of zeolite skeleton structures were eroded to collapse, and the
CEC value was still low. Therefore, the optimal $\mathrm{NaOH}$ to fly ash

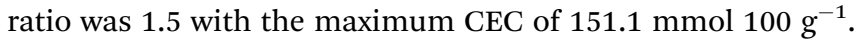

SEM was also used to study the morphology of the three samples, as exhibited in Fig. 5(a)-(c). When the ratio was 0.5, only irregular spherical particles appeared, indicating that no zeolite A was obtained. With the ratio increasing to 1.5, angular cubic crystal structure of the zeolite A particles can be clearly
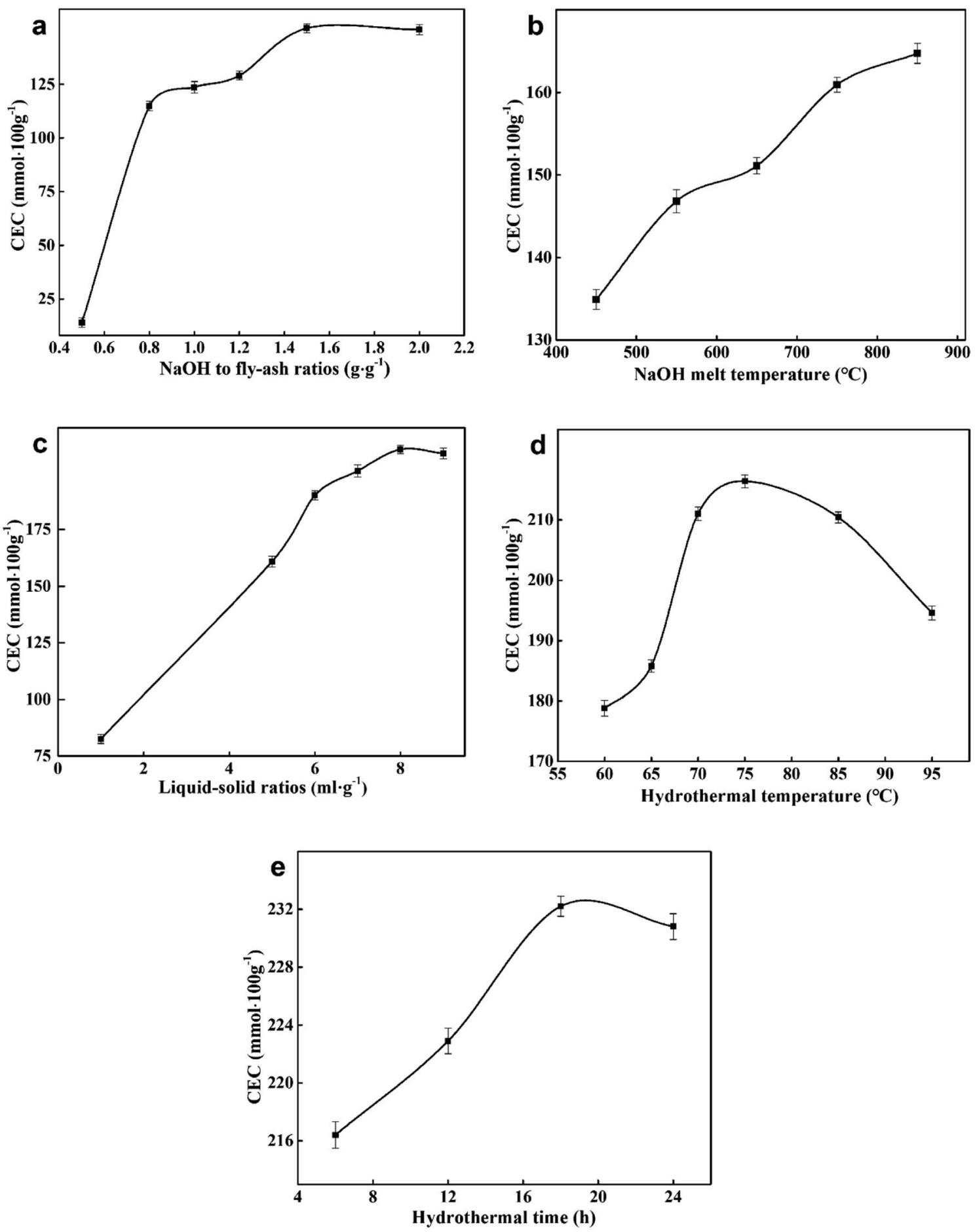

Fig. $10 \mathrm{CEC}$ of ZFA with various (a) $\mathrm{NaOH}$ to fly-ash ratios; (b) $\mathrm{NaOH}$ melt temperatures; (c) liquid-solid ratios; (d) hydrothermal temperatures; (e) hydrothermal time. 
observed. However, when the ratio increased to 2.0, the crystals became coarser and most cubic structures were seriously destroyed. As a result, the mass ratio of 1.5 was considered to be an optimized value in the investigated range for the synthesis of zeolite A. The product under this condition was named ZFA-1.

\subsection{Effects of $\mathrm{NaOH}$ melt temperatures}

The XRD patterns of ZFA at different $\mathrm{NaOH}$ melt temperatures are displayed in Fig. 4. The products were predominantly ZFA phases. The apparent characteristics of ZFA with various $\mathrm{NaOH}$ melt temperatures are shown in Fig. 5(d)-(f). It can be clearly seen that when the fusion temperature was $450{ }^{\circ} \mathrm{C}$, amorphous substance and incomplete cubic particles existed simultaneously, indicating that most silicon-aluminum compounds were free from the reaction. With $\mathrm{NaOH}$ melt temperature increasing, more complete cubic grains and larger particles were formed. In the meantime, lots of amorphous substances were significantly reduced. The effects of the $\mathrm{NaOH}$ melt temperatures on the CEC are indicated in Fig. 10(b). As the $\mathrm{NaOH}$ melt temperatures went up from $450{ }^{\circ} \mathrm{C}$ to $750{ }^{\circ} \mathrm{C}$, CEC values increased appreciably. At $850{ }^{\circ} \mathrm{C}$ there was still a small increment. Considering the energy consumption, $750{ }^{\circ} \mathrm{C}$ was chosen to be the appropriate value under which the CEC of the product was $160.9 \mathrm{mmol} 100 \mathrm{~g}^{-1}$. The product under this condition was named ZFA-2.

\subsection{Effect of liquid-solid ratios}

Fig. 6 illustrates the XRD profiles of the samples obtained at various ratios of liquid to solid ( $1 / \mathrm{s}$ ratio). It can be seen that no zeolite A formed at the $1 / \mathrm{s}$ ratio of 1 , while a new phase related to sodalite appeared. At the $1 / \mathrm{s}$ ratio of 5 , zeolite A began to appear with stratlingite impurity. With increasing the $1 / \mathrm{s}$ ratios, the pure phase diffraction peaks belonging to zeolite A were generated. Based on the above observations, it is inferred that excessively low $\mathrm{l} / \mathrm{s}$ ratio is adverse for the zeolite A conversion.

To further determine the optimal l/s ratio, the morphologies of the products with the $1 / \mathrm{s}$ ratios ranging from 1 to 9 were studied by scanning electron microscope (SEM), which revealed the evolution process of zeolite A. As exhibited in Fig. 9(a), a lot of amorphous aluminosilicate and some imperfect spherical particles with surface corrosion aggregated together. As the 1/s ratio increased, small spherical particles and amorphous aluminosilicate gradually grew into large cubic particles. Moreover, shapes of zeolite A particles became more complete and angular (Fig. 9(b) and (c)). Fig. 10(c) indicates the influence of $1 / \mathrm{s}$ ratios on the CEC of ZFA. The CEC values rapidly increased with the $1 / \mathrm{s}$ ratio ascending until the first plateau was reached (from 5 to 7 ). Then a second one could be observed in the range between 8 and 9. Accordingly, 8 of l/s ratio was taken as the optimum value and corresponding CEC was $210.4 \mathrm{mmol} 100$ $\mathrm{g}^{-1}$. The product under this condition was named ZFA-3.

\subsection{Effect of hydrothermal temperatures}

The XRD patterns of ZFA with different hydrothermal temperatures are displayed in Fig. 7. It is clearly seen that in the hydrothermal temperature ranging from $60{ }^{\circ} \mathrm{C}$ to $85{ }^{\circ} \mathrm{C}$, the peak intensity increased and zeolite A was obtained. Furthering increasing the temperature to $95{ }^{\circ} \mathrm{C}$, the peak intensity decreased and impurities appeared.

Fig. 9(d)-(f) provide the apparent features of the products at different hydrothermal temperatures. A large number of amorphous morphologies and less irregular cubic structures of products at $60{ }^{\circ} \mathrm{C}$ for $6 \mathrm{~h}$ were observed. As the hydrothermal temperature increased, intact crystal plane with larger size were generated. The obtained results are consistent with XRD profiles in Fig. 6. It should be noted that the highest CEC value of $216.4 \mathrm{mmol} 100 \mathrm{~g}^{-1}$ can be obtained at $75{ }^{\circ} \mathrm{C}$ in Fig. $10(\mathrm{~d})$. Therefore, the appropriate hydrothermal temperature was $75{ }^{\circ} \mathrm{C}$. The product under this condition was named ZFA-4.

\subsection{Effect of hydrothermal time}

In order to study the influence of hydrothermal time on the product structure, zeolite A was synthesized with different hydrothermal time. Fig. 8 shows XRD spectra of products obtained at $75^{\circ} \mathrm{C}$ from $6 \mathrm{~h}$ up to $24 \mathrm{~h}$. When the time rose from $6 \mathrm{~h}$ to $18 \mathrm{~h}$, only high purity zeolite $\mathrm{NaA}$ was produced. However, further prolonging the hydrothermal time to $24 \mathrm{~h}$, an impurity phase was detected in the products. This means that during the crystallization process, the as-synthesized zeolite A begins to transform into other crystalline phases.

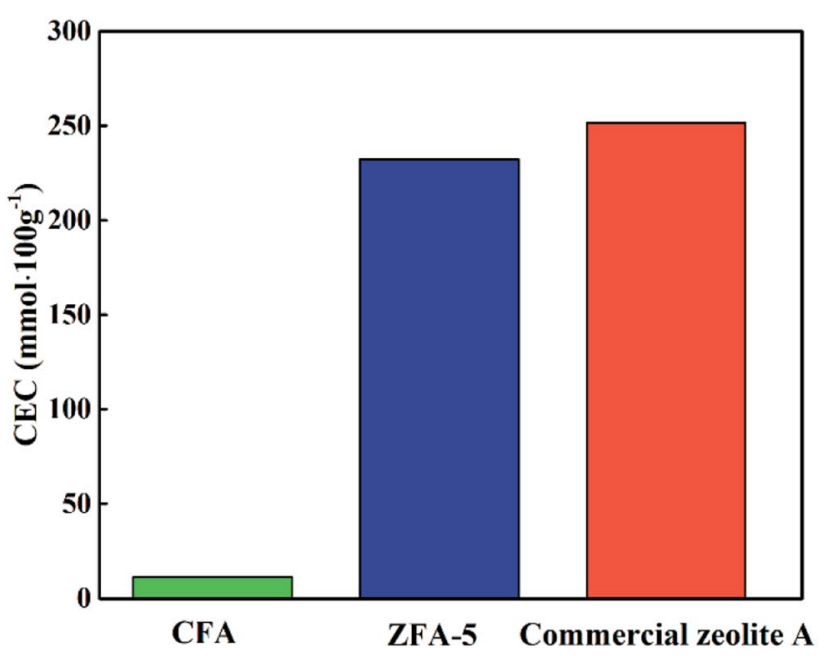

Fig. 11 Comparative CEC values of CFA, ZFA-5 and commercial zeolite A.

Table 2 Textural parameters of CFA and ZFA 1-5

\begin{tabular}{lllc}
\hline Sample & $S_{\text {BET }}\left(\mathrm{m}^{2} \mathrm{~g}^{-1}\right)$ & $\begin{array}{l}\text { Total pore volume } \\
\left(\mathrm{m}^{3} \mathrm{~g}^{-1}\right)\end{array}$ & $\begin{array}{l}\text { Mean pore size } \\
(\mathrm{nm})\end{array}$ \\
\hline CFA & 2.67 & 0.0068 & 11.9 \\
ZFA-1 & 11.8 & 0.0292 & 9.86 \\
ZFA-2 & 11.2 & 0.0256 & 8.22 \\
ZFA-4 & 34.4 & 0.0332 & 10.3 \\
ZFA-3 & 22.8 & 0.0558 & 9.60 \\
ZFA-5 & 43.7 & 0.0568 & 7.18
\end{tabular}


Fig. 9 displays the SEM pictures of products obtained at various hydrothermal time. As seen in Fig. $9(\mathrm{~g})$, it is easy to pick out that some cubic grains were covered by a large amount of amorphous substances under the hydrothermal time of $6 \mathrm{~h}$, indicating that most aluminosilicate has not yet formed zeolite. The amorphous flocculent materials disappeared when the hydrothermal time reached $18 \mathrm{~h}$. The grains obtained were more complete with a uniform size of about $1.24 \mu \mathrm{m}$ (as depicted in Fig. 9(h)). However, when the time was extended to $24 \mathrm{~h}$, the cubic structures began to collapse and the aggregation of particles became more serious (Fig. 9(i)). This indicates that optimum hydrothermal time is beneficial for the formation of zeolite A. CEC values of the zeolites synthesized at various hydrothermal time are indicated in Fig. 10(e). The best adsorption capacity $(232.2 \mathrm{mmol}$ $100 \mathrm{~g}^{-1}$ ) was achieved at the hydrothermal time of $18 \mathrm{~h}$. Note that CEC of CFA was only $11.4 \mathrm{mmol} 100 \mathrm{~g}^{-1}$ (Fig. 11), while CEC of zeolite A was about 22 times that of CFA and was notably higher than the standard requirements of QB/T1.1$2009\left(\geq 130 \mathrm{mmol} \mathrm{NH}_{4}{ }^{+} 100 \mathrm{~g}^{-1}\right)$, which was also close to the value of commercial zeolite $\mathrm{A}\left(251.6 \mathrm{mmol} \mathrm{NH}_{4}{ }^{+} 100 \mathrm{~g}^{-1}\right)$ from expensive precursors. The product under this condition was named ZFA-5.

\subsection{Characterization of the prepared zeolite A}

The significant improvement of CEC values could be discreetly correlated with pore structure changes. As can be seen from the Table 2, the BET surface areas and the total pore volume of all the zeolite A from ZFA-1 to ZFA-5 were much higher than that of CFA. The specific surface area and total pore volume obtained under the optimal conditions (sample ZFA-5) were $43.7 \mathrm{~m}^{2} \mathrm{~g}^{-1}$ and $0.0568 \mathrm{~cm}^{3} \mathrm{~g}^{-1}$ respectively. The broad aperture distribution ranged from $4.4 \mathrm{~nm}$ to $155.3 \mathrm{~nm}$, and the equivalent size is $9.08 \mathrm{~nm}$ in the Fig. 12(d). In addition, the $\mathrm{H}_{3}$ hysteresis loop type represented the existence of slit-shaped mesoporous structure which mostly produced by the accumulation of particles.

In order to further investigate the physical and chemical properties of zeolite A prepared under the optimal conditions, further detections were executed by XRD SEM, FT-IR as well as ${ }^{29} \mathrm{Si}$ and ${ }^{27} \mathrm{Al}$ NMR. The amorphous aluminosilicate and the insoluble crystalline phases were completely transformed into zeolite A with high crystallization of 94\% (Fig. 12(a)). The SEM photographs of the synthetic zeolite A powders are displayed in Fig. 12(b). It is obvious that defined cubic structure and intact crystal plane had been obtained. The size of crystal particles ranged from 1.0 to $2.5 \mu \mathrm{m}$.
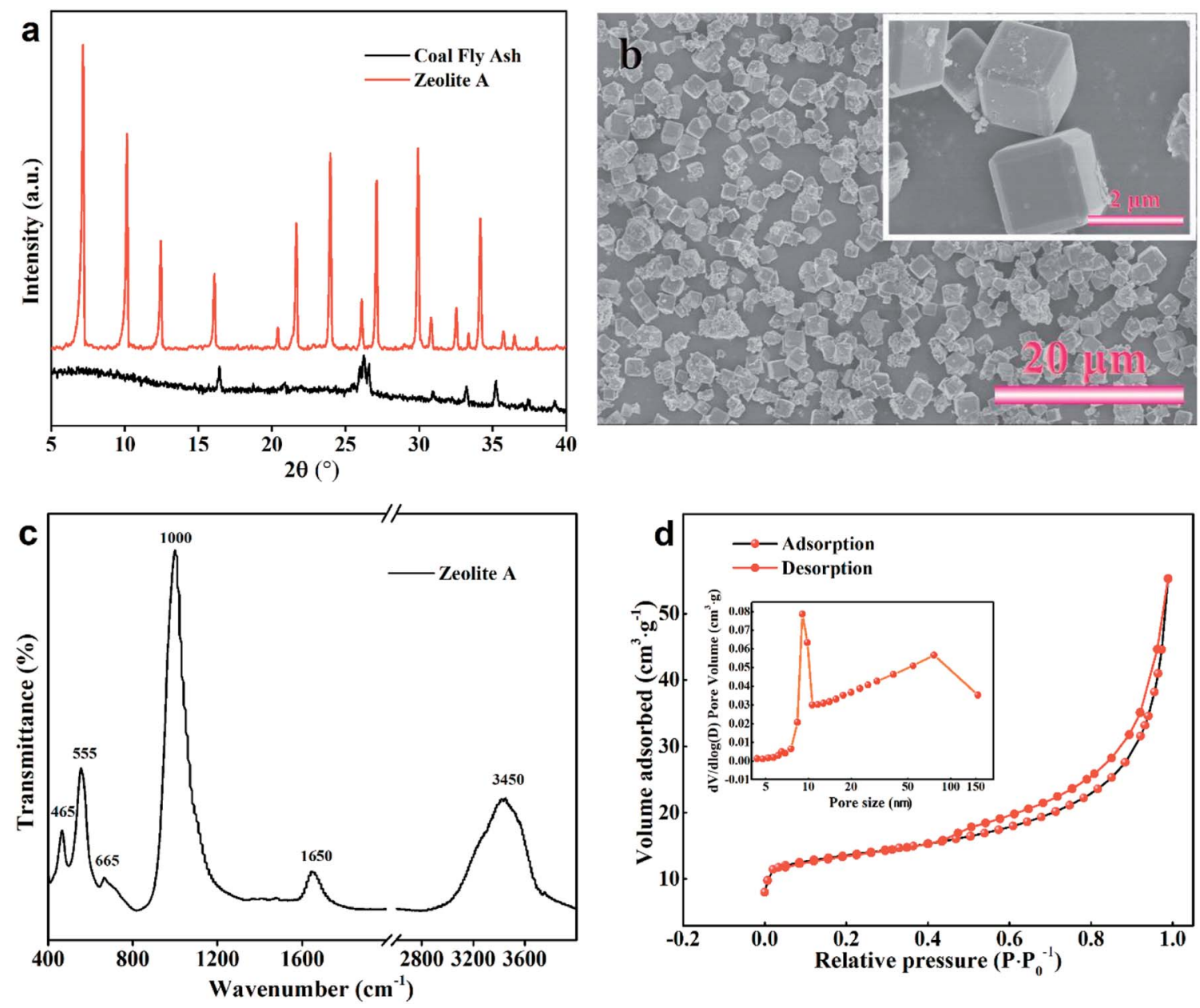

Fig. 12 Zeolite A synthesized under optimized conditions (a) XRD spectra; (b) SEM images; (c) FT-IR spectra; (d) $\mathrm{N}_{2}$ sorption isotherms. 


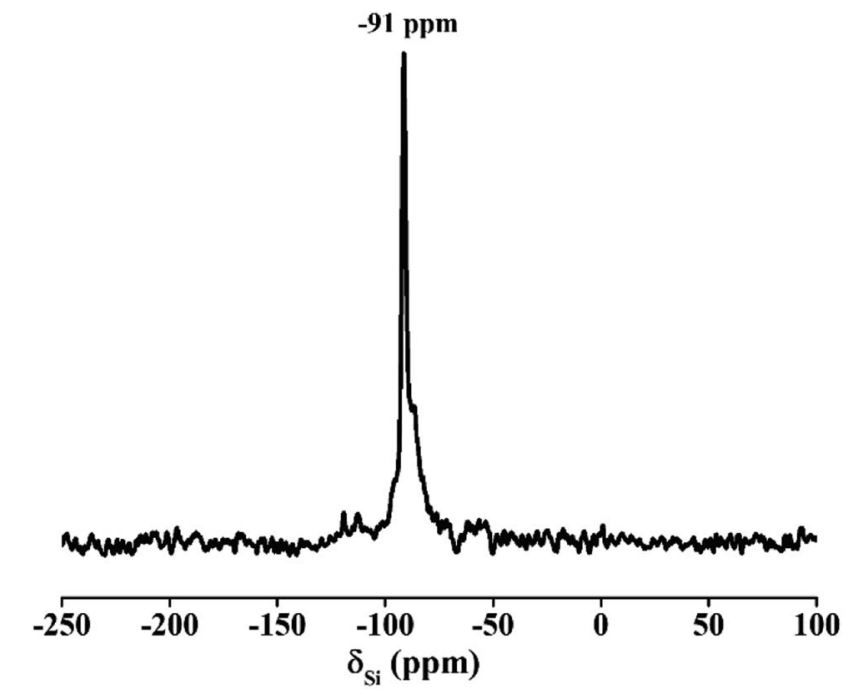

Fig. $13{ }^{29}$ Si NMR of zeolite A synthesized under optimized conditions.

As is known to all, the zeolite A framework is made up of $\beta$ cages formed by the interconnection of double 4-rings (D4R). Therefore, the arrangement of $\mathrm{Si}(\mathrm{Al})$ tetrahedron structural units can be analyzed by the FT-IR spectra. As can be clearly seen from Fig. 12(c), six distinct peaks were at about 3450, 1650, $1000,665,555$ and $465 \mathrm{~cm}^{-1}$. Among them, the characteristic peaks at $465 \mathrm{~cm}^{-1}, 555 \mathrm{~cm}^{-1}$, and $1000 \mathrm{~cm}^{-1}$ were assigned to the internal vibrations of $\mathrm{T}-\mathrm{O}(\mathrm{T}=\mathrm{Si}$ or $\mathrm{Al})$ bending, the double four-rings bending, and the internal vibration of $\mathrm{TO}_{4}$ asymmetric stretch, respectively. Furthermore, the peaks detected at 1650 and $3450 \mathrm{~cm}^{-1}$ was ascribed to the existence of the $\mathrm{H}_{2} \mathrm{O}$ and hydroxyls, respectively. ${ }^{34}$

The ${ }^{29} \mathrm{Si}$ NMR spectrum of zeolite $\mathrm{A}$ in Fig. 13 presents a unique peak at $-91 \mathrm{ppm}$, which was belonged to $(\mathrm{Si}(4 \mathrm{Al})$ tetrahedral structure) species. ${ }^{35}$ Only one high-intensity peak at 57 ppm was observed in Fig. 14. No spectral peak was found at 0-10 ppm, indicating that the $\mathrm{Al}$ is completely attributed to

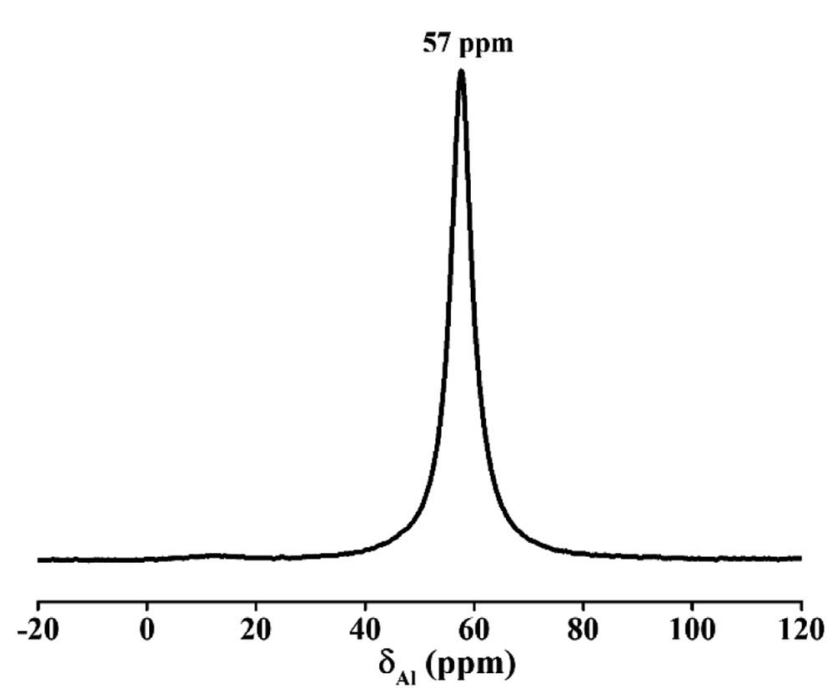

Fig. $14{ }^{27} \mathrm{Al}$ NMR of zeolite A synthesized under optimized conditions.
$\mathrm{Al}(\mathrm{O}-\mathrm{Si})_{4}$ and there were no octahedral aluminum atomic groups. ${ }^{36,37}$ This result of ${ }^{27} \mathrm{Al}$ NMR is in agreement with the previous result of ${ }^{29} \mathrm{Si}$ NMR. Both imply that the silicon and aluminum species exist in the framework of molecular sieve and the product has a high degree of crystallinity.

\section{Conclusions}

The above experimental results showed a feasible way to convert abandoned CFA into high value-added zeolite A. Several key steps are listed below:

(1) In order to remove undesired elements such as iron, acid treatment were conducive.

(2) $\mathrm{NaOH}$ fusion should be performed and the optimum conditions were $\mathrm{NaOH}$ to fly ash ratio of $1.5: 1,750{ }^{\circ} \mathrm{C}$ calcination temperature for $2 \mathrm{~h}$. In this way, quartz and mullite phases in the CFA could be converted into water-soluble salts.

(3) Zeolite A could be successfully synthesized by adding $\mathrm{NaAlO}_{2}$ into CFA to adjust the Si/Al molar ratio to 1.04 , which was consistent with the theoretical $\mathrm{Si} / \mathrm{Al}$ molar ratio of zeolite $\mathrm{A}$.

(4) The optimum hydrothermal conditions were liquid to solid ratio of $8: 1,75^{\circ} \mathrm{C}$ for $18 \mathrm{~h}$.

Based on above steps, a single crystal phase zeolite A with high crystallinity could be obtained, which showed the CEC value of $232.2 \mathrm{mmol} 100 \mathrm{~g}^{-1}$, close to that of the commercial one.

\section{Conflicts of interest}

There are no conflicts to declare.

\section{Acknowledgements}

This work was financed by the National Key Research and Development Program of China (No. 2017YFC0210403), and National Science Foundation of China (No. U1609212 and No. 51621005).

\section{Notes and references}

1 A. Mandal and D. Sengupta, Environ. Geol., 2003, 44, 180186.

2 J. L. Chen and X. W. Lu, J. Mater. Cycles Waste Manage., 2018, 20, 489-495.

3 Z. T. Yao, X. S. Ji, P. K. Sarker, J. H. Tang, L. Q. Ge, M. S. Xia and Y. Q. Xi, Earth-Sci. Rev., 2015, 141, 105-121.

$4 \mathrm{M}$. Delkash, B. E. Bakhshayesh and H. Kazemian, Microporous Mesoporous Mater., 2015, 214, 224-241.

5 S. F. Mousavi, M. Jafari, M. Kazemimoghadam and T. Mohammadi, Ceram. Int., 2013, 39, 7149-7158.

6 F. Hasan, R. Singh, G. Li, D. Zhao and P. A. Webley, J. Colloid Interface Sci., 2012, 382, 1-12.

7 J. M. Gómez, E. Díez, A. Rodríguez and M. Calvo, Microporous Mesoporous Mater., 2018, 270, 220-226.

8 T. F. Mastropietro, E. Driolia and T. Poerio, RSC Adv., 2014, 4, 21951-21957. 
9 S. M. Kwan, A. Y. L. Leung and K. L. Yeung, Sep. Purif. Technol., 2010, 73, 44-50.

10 S. Y. Wang, B. He, R. Tian, C. Sun, R. Dai, X. Li, X. Wu, X. An and X. M. Xie, J. Colloid Interface Sci., 2018, 527, 339-345.

11 J. Zhao, Y. F. Zhang, S. Q. Zhang, Q. S. Wang, M. Chen, T. Hu and C. G. Meng, Microporous Mesoporous Mater., 2018, 268, 16-24.

12 J. Zhao, Y. F. Zhang, F. P. Tian, Y. Zuo, Y. Mu and C. G. Meng, Dalton Trans., 2018, 47, 11375-11385.

13 J. Grand, S. N. Talapaneni, A. Vicente, C. Fernandez, E. Dib, H. A. Aleksandrov, G. N. Vayssilov, R. Retoux, P. Boullay, J. P. Gilson, V. Valtchev and S. Mintova, Nat. Mater., 2017, 16, 1010-1015.

14 P. C. Lei, X. J. Shen, Y. Li, M. Guo and M. Zhang, Int. J. Miner., Metall. Mater., 2016, 23, 850-857.

15 C. Covarrubias, R. Arriagada, J. Yáñez, R. García, M. Angélica, S. D. Barros, P. Arroyo and E. F. Sousa-Aguiar, J. Chem. Technol. Biotechnol., 2005, 80, 899-908.

16 N. M. Musyoka, L. F. Petrik, E. Hums, A. Kuhnt and W. Schwieger, Res. Chem. Intermed., 2015, 41, 575-582.

17 N. Meller, K. Kyritsis and C. Hal, Cem. Concr. Res., 2009, 39, 45-53.

18 A. Shoumkova and V. Stoyanova, J. Porous Mater., 2013, 20, 249-255.

19 K. S. Hui and C. Y. Chao, J. Hazard. Mater., 2006, 137, 401409.

20 H. Tanaka, S. Fujimoto, A. Fujii, R. Hino and T. Kawazoe, Ind. Eng. Chem. Res., 2008, 47, 226-230.

21 M. Mezni, A. Hamzaoui, N. Hamdi and E. Srasra, Appl. Clay Sci., 2011, 52, 209-218.

22 G. Garcia, W. Aguilar-Mamani, I. Carabante, S. Cabrera, J. Hedlund and J. Mouzon, J. Alloys Compd., 2015, 619, 771-777.
23 Y. N. Ma, C. J. Yan, A. Alshameri, X. M. Qiu, C. Y. Zhou and D. Li, Adv. Powder Technol., 2014, 25, 495-499.

24 A. Á. B. Maia, R. F. Neves, R. S. Angélica and H. Pöllmann, Appl. Clay Sci., 2015, 108, 55-60.

25 S. S. Bukhari, J. Behin, H. Kazemian and S. Rohani, Fuel, 2015, 140, 250-266.

26 T. V. Ojumu, P. P. Du and L. F. Petrik, Ultrason. Sonochem., 2016, 31, 342-349.

27 W. Franus, M. Wdowin and M. Franus, Environ. Monit. Assess., 2014, 186, 5721-5729.

28 A. M. Cardoso, A. Paprocki, L. S. Ferret, C. M. N. Azevedo and M. Pires, Fuel, 2015, 139, 59-67.

29 K. Ojha, N. C. Pradhan and A. N. Samanta, Bull. Mater. Sci., 2004, 27, 555-564.

30 J. L. X. Hong, T. Maneerung, S. N. Koh, S. Kawi and C. H. Wang, Ind. Eng. Chem. Res., 2017, 56, 11565-11574.

31 L. Zhu, R. Zhu, L. Xu and X. Ruan, Colloids Surf., A, 2007, 304, 41-48.

32 C. F. Wang, J. S. Li, L. J. Wang and X. Y. Sun, J. Hazard. Mater., 2008, 155, 58-64.

33 L. Ding, H. Yang, P. Rahimi, O. Omotoso, W. Friesen, C. Fairbridge, Y. Shi and $\mathrm{S}$. $\mathrm{Ng}$, Microporous Mesoporous Mater., 2010, 130, 303-308.

34 X. Zhang, D. Tang and G. Jiang, Adv. Powder Technol., 2013, 24, 689-696.

35 J. Tan, Z. Liu, X. Bao, X. Liu, X. Han, C. He and R. Zhai, Microporous Mesoporous Mater., 2002, 53, 97-108.

36 M. Choi, H. S. Cho, R. Srivastava, C. Venkatesan, D. H. Choi and R. Ryoo, Nat. Mater., 2006, 5, 718-723.

37 T. O. Do, A. Nossov, M. A. Springuelhuet, C. Schneider, J. L. Bretherton, C. A. Fyfe and S. Kaliaguine, J. Am. Chem. Soc., 2004, 126, 14324-143245. 